\title{
SOME THOUGHTS ON LAW TEACHING AND THE SOCIAL SCIENCES
}

\section{Alexander Hamilton Frey $\dagger$}

There has been much talk in recent years, emanating largely from the law schools of Columbia and Yale Universities, about law as one of the social sciences. Yet neither of these schools, nor any other law school, has attempted to develop a program of studies in which this thought appears as a reality instead of merely an interesting or challenging suggestion. Many explanations might be offered for the continued failure of law school curricula to reflect the interrelation between law and such other studies as economics, sociology and political science; it is my belief that one of the foremost factors has been the presence, among the required first-year studies of practically all law schools, of a number of courses of "synthesis" such as Agency, Contracts and Torts,-courses which purport to assemble supposedly common legal factors from widely diverse transactional fields.

The conventional procedure in such courses is to evolve or induce a general principle from a variety of specific situations which may be, and usually are, quite unrelated factually. Not infrequently the facts of these illustrative cases are connected with fairly well-defined economic or social institutions, such as banking or taxation or the family. But since neither instructor nor student can pretend to expert or detailed knowledge of all these fields, the problems are of necessity divorced from their factual background and only the abstractions of legal theory are investigated-a practice which completely ignores the conception of law as a social science.

These abstract courses are objectionable not merely because they omit any intensive study of the institutional background of the specific disputes dealt with, but also because they are unsound pedagogically: (I) they present a distorted impression as to the degree of certainty in the law; (2) they occupy the student's time and energy with the acquisition of information and technical skill which are less important than the knowledge and techniques which he might otherwise develop during the same period if a considerable number of his law school courses should focus upon a human institution as a field of fact rather than upon a legal concept.

The course in Agency will serve as a convenient illustration. Does the law of Agency deal with the legal problems arising out of the conduct of affairs by others ? ${ }^{1}$ Does it relate to the legal problems involved when one

$\dagger$ A. B., Igrg, Yale University ; M. A., I920, Columbia University ; LL. B., I921, J. S. D., I925, Yale University; Professor of Law, University of Pennsylvania Law School; author of articles and book reviews in various legal periodicals.

${ }^{1}$ See Steffen, Cases on the Law of Agency (1933) I. 
person is employed to act for another? ${ }^{2}$ Does it concern legal problems resulting when, by mutual consent, one person acts on behalf of another and subject to his control ? ${ }^{3}$ It is not my thought to quarrel with anyone's definition of Agency or to present one of my own. The foregoing suggestions may for some purposes have much in common; for other purposes they may be vastly dissimilar. If separately or collectively they suggest the subject matter of an orthodox course in Agency, of any standard casebook on that topic, the enormous variety of possible fact-situations embraced by such a course is at once apparent. Agency so conceived traverses the whole range of human activity. This is also true to almost the same extent of a number of other courses such as Contracts, Torts, Quasi-contracts, Trusts, Conflict of Laws, and Business Associations.

Obviously a stated principle or rule which adequately summarizes or even justifies a number of decisions in one field of fact may lead to an unjust or undesirable result when applied to other situations which the rule might verbally (thecretically) control. Any casebook or treatise relating to one of these abstract subjects, these courses of "synthesis", abounds in instances illustrating this truism. Let us for instance consider three cases. First, $A$ borrows $\$$ roo from $B$, and as security in case of non-payment gives $B$ a power of attorney to sell a designated painting belonging to $A$ then on display for sale in a Manhattan art gallery. A dies shortly after making default in repayment and $B$ seeks to enforce his power of attorney. Second, $A$ and $B$ form a partnership for a ten-year period; at the end of five years $B$ receives notice from $A$ of $A$ 's "withdrawal" from the firm; $B$ seeks to remain in possession of the firm assets for the purpose of carrying on the business for the next five years. Third, $A$ makes a gift to $B$ of a check for $\$ 100$; $B$ at once gets the check certified; $A$ shortly thereafter orders the bank upon which the check is drawn to stop payment thereon; $B$ seeks to obtain payment of the check from the bank. It seems patent that very different economic problems underlie each of these situations and that if these were undecided cases their solution would not be facilitated by reference to general principles expressed in terms of the power of a principal to terminate the authority of an agent.

Turning at random to the recently published Agency Restatement I happen upon Section 388 which states that "unless otherwise agreed, an agent who makes a profit in connection with transactions conducted by him on behalf of the principal is under a duty to give such profit to the principal". Verbally this statement might apply to such diverse situations as ( $\mathrm{I}$ ) a chauffeur's getting a "commission" in buying gasoline or tires

\footnotetext{
2 See Mechen, Outlines of the Law of Agency (3d ed. I923) § Ir.

${ }^{3}$ See Agency Restatement (Am. L. Inst. I933) § I.
} 
for his employer's car, (2) an express company's obtaining a rebate from a railroad, (3) transactions between corporations having interlocking directorates or certain common officers which result more favorably to one corporation than the other, and (4) profits acquired by promoters in the organization of a corporation. To me it would seem almost presumptuous if anyone primarily schooled merely in the abstractions of the $P-A-T$ triangle should undertake to lay down a rule of law for the determination of problems arising out of such diverse and complex fields. ${ }^{4}$

Countless other instances might be presented where the principles developed by authorities in such a subject as Agency are so broad in their probable implications that they cover, or may be used to cover, an enormous range of situations, many of which are parts of human institutions as to whose customs, practices and needs the Agency authority cannot conceivably have expert knowledge. To this it may be objected that a rule of law such as that quoted would not be deemed by Agency experts to control all the suggested situations; it would be regarded as merely stating a prima facie case for the indicated result, with the way open for a demonstration of the inapplicability of the rule in any given situation. There is, however, nothing in such rules as usually phrased to suggest this limitation, and furthermore, whence comes the assurance of the Agency authorities that even this qualified statement as to the prima facie result is, or ought to be, the law in every conceivable field of conduct through representatives to which it is applicable? ${ }^{5}$ Would it not be far more desirable to develop lawmen who are intimately familiar with conditions in one of the worlds of banking, or of insurance, or of taxation, or of the family, or of marketing, or of transportation, etc., and to allot to them the problem of determining what is, or ought to be (if no rule has crystallized), the law in such fields?

Of late years many indications have suggested that not a few law teachers are plagued by a sense of the futility of attempting to utilize with intellectual honesty the broad general principles developed in courses such as Agency, Contracts and Torts, where the application of such principles is not limited to specific fields of fact. Some compilers of law teaching materials have attacked this problem by grouping their cases along factual rather than conceptual lines. Dean Green was perhaps a forerunner in this group when, in his book, The Judicial Process in Tort Cases, ${ }^{6}$ he assembled

- The Restatement illustrations to this Section concern the activities of a real estate broker, an insurance agent, the purchasing agent for a railroad and the purchasing agent of a large restaurant.

'Lest I be misunderstood, I hasten to state that I concede value to judges and practitioners of able treatises or RESTATEMENTS on such subjects as Agency, Contracts and Torts; they facilitate the search for analogies upon which our system of stare decisis is based, not only by presenting useful classification of vast masses of cases, but also by doctrinal discussions of conflicting or yet-to-be-decided cases. I also think that treatises on Automobiles and Liquor Prohibition are useful; but I should not approve of requiring law students to pursue courses on such topics.

- Green, The Judicial Process in Tort Cases (ig3i). 
his cases in accordance with the type of harm involved in the tort. Professor Havighurst has carried forward somewhat the same idea in his experimental Contract Cases ${ }^{7}$ by making the nature of the transaction which the contract concerns the focal point in his subdivisions. Professor Steffen's recently published casebook on Agency ${ }^{s}$ extends this unorthodox presentation to that subject. Especial dissatisfaction with the course in Agency is noticeable in not a few law schools, and there is a perceptible movement toward either cutting down the number of teaching hours devoted to this course or banishing it from the curriculum as a separate course by absorbing the treatment of its major doctrines into commercial law courses, principally those dealing with business associations. It is my belief, however, that this dissatisfaction does not spring merely from a poor choice or grouping of teaching materials, as the novel features of Steffen's book imply, ${ }^{9}$ but primarily from the vast scope of the transactions, the fields of fact, embraced by any orthodox concept of Agency, a difficulty not overcome by Steffien's approach.

It would seem that for the same reason Green and Havighurst also fall short of their objectives. Their casebooks aim to present teaching materials in which the character of the fact situation out of which the legal dispute arises will not be lost sight of in the process of considering the legal concepts involved. But these books likewise include such a wide range of factual categories that intelligent comprehension of the vital problems in each field of fact is virtually impossible of achievement, since neither instructor nor student can surmount the impossibility of being a general expert.

The solution of this dilemma would seem to lie in the introduction into the law school curriculum of a number of courses in each of which the legal problems dealt with would all be focused about a single economic, political or social institution, and in absorbing into such courses the specific rules now imperfectly presented in abstract courses of "synthesis". Because of an ancient historical survival from a comparatively simple legal era when all substantive law was conceived of as relating either to Crimes, Torts or Contracts must the first year program of law studies go on forever including courses on these topics? If it be insisted that the work of the first year should be "introductory" to more specialized studies to be pursued thereafter (not a self-evident truth), then it is time to recognize other all-inclusive major classifications, factual rather than conceptual, of legal controversies,

'Professor Havighurst's materials have not as yet been formally published. For an admirably written partial exposition of his view, see his article, Services in the Home-a Study of Contract Concepts in Domestic Relations (1932) 4I Y ALE L. J. 386.

"STEFFen, op. cit. supra note $\mathrm{I}$.

- Steffen's thesis is that "the center of gravity in the Agency field has long since shifted to the problems of the business organization". Hence his book abounds in cases concerning corporations, partnerships and business trusts, cases exemplifying his view that modern principals and agents are in most instances associations and not single individuals. 
such as labor transactions, credit transactions and transactions for the acquisition, disposition and conservation of property.

Perhaps it will be maintained that while it would be wholly admirable to consider cases the facts of which are related to a recognized economic or social or political institution in their institutional settings, the facts of the majority of cases have no such background which might be studied, and there must be some technique for deciding these latter cases as well. Several responses suggest themselves. First, if the attention of able law teachers in a number of courses should be concentrated upon such an institution rather than upon a legal concept, new groupings and classifications would develop whick. would reveal an institutional background to many situations heretofore regarded as isolated. Second, the law student needs to be discouraged from, rather than trained in, approaching the solution of legal problems from the standpoint of broad general principles. Most human beings, and law students are certainly not exceptions, are all too prone to substitute "good" reasons for "real" reasons, to be content to cease delving for explanations or justifications if they can find a convenient conceptual category upon which to base a result, although the concept may be just another way of stating the result; the digging for "real" reasons is so much harder and ofttimes so much less satisfying. Third, abstract courses of "synthesis" do not provide training in a satisfactory method of disposing of the supposed legal controversies which have no institutional background.

It would seem patent that every specific legal problem is either a hitherto decided case, in which event the doctrine of stare decisis normally operates and determines the result, or else it is a hitherto undecided case, the decision of which will make new law. The decision in these latter cases can have no rational basis save expediency, that is, the court's conclusion as to the soundest policy, economic, social or political as the case may be. The value of the social sciences in the solution of the undecided case is thus obvious; in this realm what the lawman, be he attorney, judge, teacher or writer, requires is, first, standards of human values, and, second, facts and techniques for .gathering and evaluating new data relative to deciding between competing or conflicting standards, which no amount of study of legal abstractions can furnish.

In any system of jurisprudence dominated by the rule of stare decisis students of law must be trained to know, to be able readily to determine. what controversies have heretofore been decided by authoritative courts, and what these decisions have been. This involves a knowledge of the legal past; an understanding of the historical development of legal institutions, of legal rules and principles, of legal processes; a familiarity with a vast number of prior decisions (although this will at best always be fragmentary), and with a convenient method of classifying such decisions so that one may readily 
recall or discover what has been decided in the past. This much the better law schools, or at least the better law teachers, do admirably. But they do too little else. The students receive far too little training in handling the ever-expanding field of the hitherto undecided case. More seriously still, early and incessant training in abstract courses of "synthesis", courses such as Agency, Contracts and Torts, tends to dull the students' perceptions as to which are the decided cases and which the undecided.

A present controversy is a decided case if in the past a controlling or persuasive court has rendered a decision in the same or an analogous situation. When are two legal controversies analogous? Is it not when they involve substantially the same problems (I) of legal doctrine and (2) of human expediency? If two controversies involve the application of the same legal concept to virtually identical facts (did $A$ acquire "possession" from $B$ ? did "title" pass from $X$ to $Y$ ? was $D$ "domiciled" in New Jersey or Pennsylvania?), but the underlying economic or social or political problems are vastly dissimilar (revocability of a power of attorney given to secure a loan, or the effectiveness of an alleged gift; existence of an insurable interest, or acquisition of risk of loss; liability to taxation, or legitimacy of offspring, etc.), are the controversies analogous? I should suppose not; and yet constant concentration of attention almost exclusively upon the minutiae of legal doctrine blinds one to these important distinctions-distinctions with a difference, the observance of which is quite consistent with adherence to the principle of stare decisis. ${ }^{10}$

Brilliant essays have been written on the problem of the undecided case and how it should be dealt with. ${ }^{11}$ Far too little attention has been given by able scholars to the preliminary problem as to which of the multitude of controversies that may come into a lawyer's office or before a court are the undecided ones. To require of first-year law students, before they are equipped to discriminate, that they attempt to evolve broad legal principles, supposedly applicable to highly diverse fields of fact, is to render them a disservice. $^{12}$ It is not a little like raising a child on a diet of proverbs. So much time and effort has been expended on the development of these generalities that comparatively little is known about what the courts have really done in the past and hence are likely to do in the future, what in short the law is.

${ }^{20}$ See Oliphant, $A$ Return to Stare Decisis (I928) 6 Am. L. ScHool. REv. 215.

${ }^{11}$ See, for example, Dickinson, The Problem of the Unprovided Case (1932) 8I U. of PA. L. Rev. Ir5; and Goble, Laze as a Science (I933) 37 Scientific Monthly 229.

${ }^{22}$ Any logical process inevitably involves generalizations. The problem is as to the scope of the generalizations which the first-year student should be encouraged to formulate. Courses of "synthesis" should be offered to the student only after he has already examined the legal problems in a variety of courses devoted to separate fields of fact, so that he may be in a position intelligently to determine what common legal threads do run through such courses which might be woven into a useful pattern. 
The classic explanation of this orthodox procedure is that the development of broad principles leads to greater certainty. ${ }^{13}$ I am not one who decries an urge for certainty in the law but $I$ abhor an illusion of certainty which can but enhance uncertainty. The greatest need of the present legal era is for more facts-facts as to the kinds of economic, social or political controversies which courts and administrative tribunals are being called upon to consider; facts as to how, and upon what basis, and with what rapidity, and at what cost these controversies are being settled. Without such facts, and many others, statements as to general legal principles must be either arbitrarly or unintelligently formulated, and hence cannot save by the sheerest accident promote certainty, for human laws are merely devices for regulating conduct to a desired end; no alleged legal rule will long be followed which tends to retard the attainment of the desired result. ${ }^{14}$

The undecided legal controversies might, for law teaching purposes, be divided into two groups. First, there is the undecided case as to which there may be available data which will shed light upon the economic or social or political expediency of one decision as contrasted with another, and thus upon the desirability of one or another proposed standard of human conduct. This involves training students of law in a knowledge of the best that is known and thought in the fields of economics, of sociology, of politics, insofar as such knowledge impinges upon selected legal problems; and in a comprehension of the presence or absence of connection between law and these other social sciences, and their possible interrelation; but all this with a high degree of skcpticism, an unyielding demand for proofs, a piercing of pretensions. While I believe that when courts and attorneys are confronted with hitherto undecided cases (and this group is rapidly expanding) they should neglect no reasonable source of possible enlightenment in the determination of the controversy, and while I may have somewhat more faith than many of my legal colleagues in the aid which may be derived from the other social sciences in this process, I have no illusions about the inexactness, the unscientific character, of many of the past and current pronouncements of these kindred pseudo-scientists. ${ }^{15}$ Nevertheless, it is frequently possible for able and informed lawyers to develop their own techniques for gathering so-called economic data that will shed much light upon complicated legal controversies. And I see no reason why the pompousness, or at any rate the lack of professional humility, which many economists share with the more ardent jurisprudentists, should discourage the utilization of such aids.

${ }^{13}$ Compare Frank, Law and the Modern Mind (1930).

${ }^{13}$ See Cook, Scientific Method and the Law (I927) I5 Jomns Hopkins Alumin MagaZLNE 213.

${ }^{25}$ During the year 1929-1930 I was the holder of a fellowship from the Social Science Research Council. The most valuable lesson I learned from that experience was that the field of economics is just about as saturated with arm-chair musings, with unproved and unprovable generalities, as is the field of law. 
As heretofore indicated, to accomplish this training the law school curriculum should afford the student an opportunity, from the beginning of his law course, to explore in concentrated form the legal problems associated with separate human institutions. If training in the general principles now involved in courses such as Agency, Contracts and Torts is deemed to be an indispensable part of an adequate legal education (and I hasten to concede that such principles are contributing though not necessarily controlling factors in the decision of the undecided case), would it not be feasible to allocate the various segments of this type of training to particular institutional courses? For instance, a course in Insurance could be devised in which the student would learn a great deal about the legal problems symbolized by such terms as offer, acceptance, consideration, authority, revocation, adoption, etc., without having first been subjected to a conventional course in either Contracts or Agency. At the same time he would be studying the history of insurance, the normal operation of various types of insurance businesses, problems of investment of insurance assets, the various needs for insurance, etc., which would enable him to approach legal problems in this field with an enlightenment no study merely of Agency or of Contracts could possibly produce. Similarly, a course in Banking might be developed that would acquaint the student with other generalities now encompassed by the courses in Contracts and Agency, and would at the same time equip him with specific and detailed knowledge of this institution. A course in Transportation might present a favorable field in which to familiarize the student with many of the general principles of tort law. Much of the material now separately taught (with varying degrees of ability) in college social science courses should be included in such law courses where it could be considered more profitably in connection with a definite legal problem. This might require expanding the law course and admitting students at the end of their third or even second years in college.

There remains to be considered the problem of the undecided case to the solution of which nothing even remotely resembling a scientific approach (an ability to demonstrate uniformity of cause and effect) is possible. These are controversies in which the facts are not related to a recognized economic or social or political institution, and which therefore have no institutional setting against which they might be studied. Such cases are either unconnected with any crystallized function of human activity and hence are unrelated to any recognized values or standards of human conduct, or there is no evidence, no record of human experience, that would be relevant in determining which of several possible decisions would best conform to some applicable standard of value. To the solution of these problems there is no rational approach. To their determination the only light that can be brought is an inner philosophical one in the development of which judge and attorney 
should collaborate; in the realm of these cases the greatest service which a law school can render to its students is to lead them in developing a sense of proportion, a set of personal and social values, to guide them, in short, in their search for the "good life". In the last analysis the problem of deciding any hitherto undecided legal controversy, even one in whose solution the social sciences may be of aid, is largely philosophical, because of the inescapable necessity of arriving at a preliminary judgment as to ultimate values; the contribution of the social or other sciences consists not in formulating but in verifying this judgment. But the study of institutional courses such as above suggested should open to the law student new vistas of understanding of the problems and points of view of his fellowmen, and thus assist in the development of those qualities requisite to the decision of any undecided case.

The suggestion is often heard that the primary function of a law school should be to train its students in "legal thinking", in the development of a "lawyer's mind". It cannot be gainsaid that no law school which professes to have as its primary objective the training of future practitioners should neglect to familiarize the student with prevailing conditions in the legal world, even though the present be regarded as a short interim period. But this ought not to require complete subservience to the past in legal education. Moreover, no violent change would occur even if a legal curriculum including many more "institutional" courses than now obtain, should achieve widespread adoption. A considerable transformation in the technique of bench and bar in succeeding generations would surely result, but this would be evolutionary. In such matters reforms come but slowly, largely from a succession of compromises, and meantime legal problems continue to arise and their anticipation or solution proceeds along somewhat familiar lines.

At least lip-service is still frequently rendered to the conception of a lawyer as an officer of the court, an assistant to the judge in the administration of justice-according-to-law. Too long has this fine tradition of the bar been neglected in American legal education; the time has come for law schools, especially university law schools which aim at something more than the mass production of legal technicians, to devise a curriculum that will convert this pious platitude into a reality. Constant thinking along these lines, courage to experiment, willingness to lead rather than to follow though the goal be uncertain, generous exchange of ideas, must be forthcoming in great abundance from the leading legal educators, if American legal education is to be brought into line with the needs of a rapidly transforming society. 